\title{
Complete Bicornuate Uterus with Complete Longitudinal Vaginal Septum
}

\author{
Suwal A, ${ }^{1}$ Kumar A' \\ 'Department of Obstetrics and gynaecology, College of Medical Sciences Teaching Hospital, Bharatapur, Nepal.
}

\section{ABSTRACT}

Bicornuate Uterus is a type of lateral fusion disorder of the mullerian ducts. According to the American Fertility Society Classification of Mullerian Anomalies, bicornuate uterus is a class IV anomaly. Incidence of this anomaly varies. This may affect a woman's obstetric, as well as her gynecologic outcome. Here we present a 23 year primigravida at 38 weeks and 5 days gestation with footling breech presentation. She was identified, during cesarean section, of having complete bicornuate uterus with complete longitudinal vaginal septum.

Keywords: bicornuate, pregnancy, uterus, vaginal septum

\section{INTRODUCTION}

Congenital anomalies of the uterus are often asymptomatic and therefore unrecognized. They occur in $2-4 \%$ of fertile women with normal reproductive outcomes. ${ }^{1}$ The bicornuate uterus is one of the symmetric-unobstructed disorders of lateral fusion of the Mullerian Ducts with $26 \%$ frequency. ${ }^{2-3}$ It refers to a uterus with indented fundus (arbitrarily defined as $\geq 1 \mathrm{~cm}$ ) and generally normal vagina but a longitudinal vaginal septum may be associated. ${ }^{4}$ It may be complete (with two cervices) and partial (with one cervix). ${ }^{3}$ Pregnancy outcomes are close to those of the general population. However, complications such as pregnancy loss, preterm labor, or malpresentations may occur. ${ }^{5}$

\section{CASE REPORT}

A 23 year primigravida at 38 weeks gestation came with per vaginal leaking for 18 hours and pain abdomen for 10 hours. She had antenatal checkups elsewhere. She had ultrasonography done twice during her antenatal visits but no abnormality of the genital tract was detected. She was married for two years and had not used any contraception. Her menstrual history was regular with dysmenorrhoea and without menorrhagia. She did not give the history of dyspareunia.

On per abdomen and vaginal examinations, footling breech presentation was diagnosed and emergency cesarean section was planned. After all basic investigations, cesarean was performed.

Fetus was found to be in double footling presentation during the surgery. After exteriorizing the uterus, an indentation over the fundus and two endometrial cavities with a complete septum was identified. Right horn was the one containing the fetus and the placenta. The uterine septum was excised. Per speculum and per vaginal examinations after operation revealed two cervices and a complete vaginal septum.

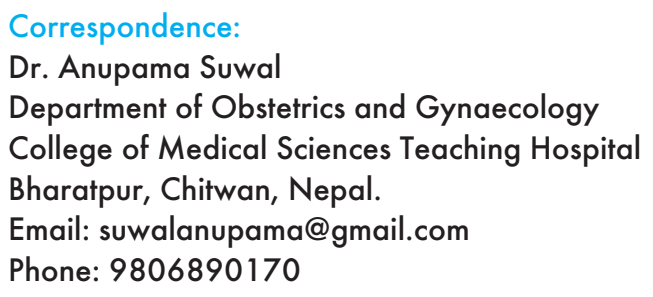



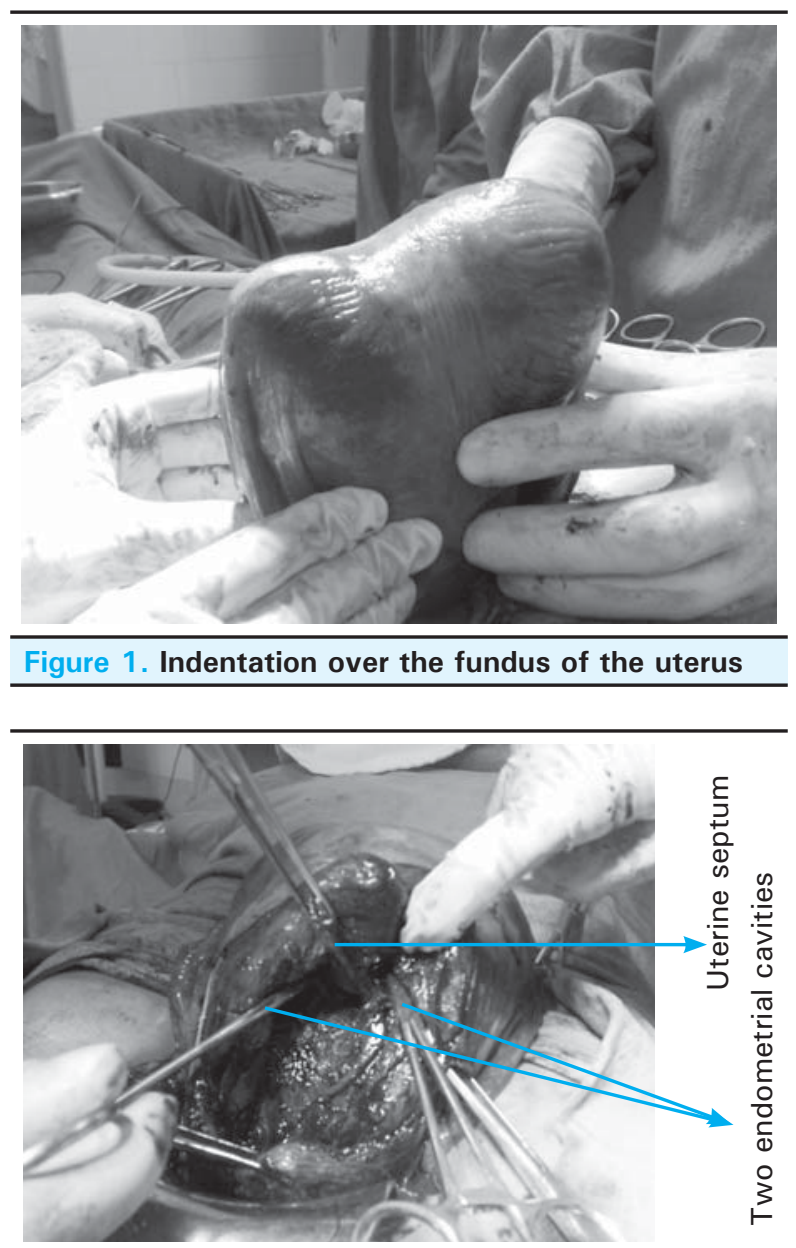

Figure 2. Two endometrial cavities divided by a septum

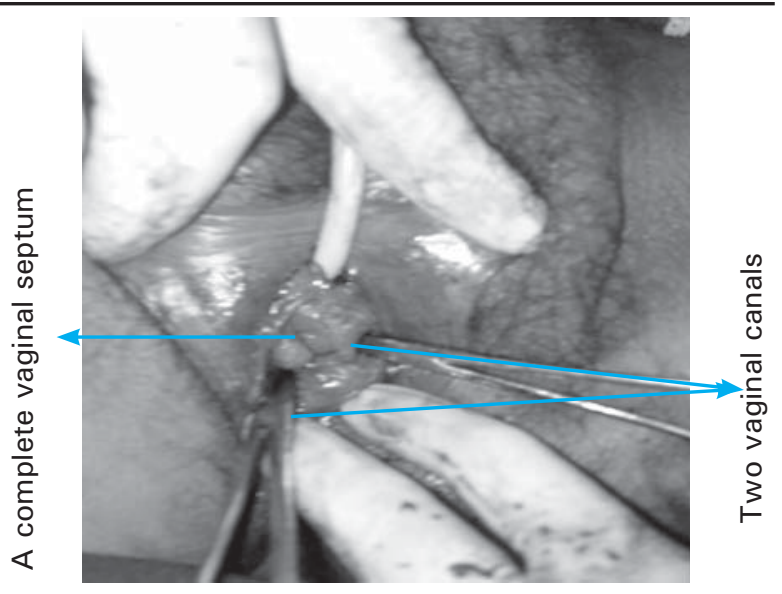

Figure 3. A complete vaginal septum with two vaginas

\section{DISCUSSION}

The bicornuate uterus and vaginal septum are congenital defects of the female genital tract. Although some uterine anomalies can cause infertility, most patients are able to conceive without difficulty. However the incidences of spontaneous abortion, premature birth, fetal loss, malpresentation, and cesarean section are clearly increased when a uterine anomaly is present. It is impossible to predict which patients with uterine anomalies will have these problems. ${ }^{3}$

The etiology of reproductive failure in patients with uterine anomalies remains unclear. However, the implantation of the placenta in inadequately vascularized septum, associated cervical incompetence, luteal phase insufficiency, and distortion of the uterine milieu have all been implicated in the etiology of increased reproductive loss. Interestingly, it has been reported that the chance for a live born child increases with each pregnancy loss. $^{3}$

The absence of mullerian-inhibiting factor results in persistence of mullerian ducts in the female. These ducts grow caudally and along with the mesonephric ducts it is enclosed in the peritoneal folds that later give rise to the broad ligaments of the uterus. At about 10 weeks' gestation, the two distal portions of the mullerian ducts approach each other in the midline and begin to fuse even before they reach the urogenital sinus. The fused ducts form a tube with a single lumen called the uterovaginal canal, which then inserts into the urogenital sinus at Mullerian tubercle. This canal forms the uterus and upper portion of the vagina. In a normal female, the uterine corpus and cervix differentiate, and the uterine wall thickens by 12 weeks' gestation. Initially, the upper pole of the uterus contains a thick midline septum that undergoes dissolution to create the uterine cavity which is usually completed by 20 weeks. The unfused cephalad portions of the mullerian ducts become the fallopian tubes. Any failure of lateral fusion of the two mullerian ducts or failure to reabsorb the septum between them results in separate uterine horns or some degree of persistent midline uterine septum. Moreover, vaginal agenesis is caused by failed caudal migration of these ducts. The distal third of the vagina develops from the bilateral sinovaginal bulbs, which arise from the urogenital sinus. The most inferior portion of the uterovaginal canal becomes occluded by a cellular mass derived from the sinovaginal bulbs, termed the vaginal plate. The cells of the vaginal plate desquamate during the second trimester, allowing for full canalization of the vaginal lumen. Defects in vertical fusion caused by incomplete canalization of this plate can lead to a persistent transverse vaginal septum. Septa can develop at different levels within the vagina and can be of various thicknesses. ${ }^{6}$

A bicornuate uterus is caused by incomplete lateral fusion of the mullerian ducts. It is characterized by two separate but communicating endometrial cavities. Failure of fusion may extend to the cervix, resulting in a 
Suwal et al. Complete Bicornuate Uterus with Complete Longitudinal Vaginal Septum

complete bicornuate uterus, or may be partial, causing a milder abnormality. Several studies suggest that women with a bicornuate uterus can expect reasonable success in delivering a living child (about $60 \%$ ). Rock reported that a bicornuate uterus was present in $55 \%$ of women with an anomalous uterus who had a satisfactory reproductive history. ${ }^{7}$ Only $14 \%$ of women with poor reproductive performance had a bicornuate uterus. As with many uterine anomalies, premature delivery is a substantial obstetric risk. Heinonen and colleagues reported a $28 \%$ abortion rate and a $20 \%$ incidence of premature labor in women with a partial bicornuate uterus. Women with a complete bicornuate uterus had a $66 \%$ incidence of preterm delivery and a lower fetal survival rate. ${ }^{8}$

Early pregnancy loss is significantly more common with a septate than with a bicornuate uterus. ${ }^{9}$ Buttram and Gibbons noted pregnancy loss rates in the first 20 weeks of $70 \%$ for bicornuate uterus compared with $88 \%$ for septate uterus. ${ }^{10}$

A Y-shaped uterus on hysterosalpingography may represent either a uterine septum or bicornuate uterus. In these cases, the external contour of the uterine fundus must be evaluated using MR imaging, high resolution sonography, or laparoscopy. A smooth fundal contour is consistent with a diagnosis of uterine septum.

The differentiation between a bicornuate and septate uterus is less confidently achieved by traditional transvaginalsonographic techniques. Ideally, measurement of the angle between the two endometrial cavities and analysis of the fundal shape helps to differentiate between a bicornuate uterus (angle $105^{\circ}$ ) and a septate uterus (angle $\left.75^{\circ}\right) .{ }^{11}$ Combining TVS findings with SIS provides accuracy up to $90 \%$ to distinguish the two anomalies. Three-dimensional sonography is considered by some to be the best noninvasive method for distinguishing between them as its sensitivity is $93 \%$ and specificity of $100 \%$ in experienced hands. ${ }^{4,12}$ The technique allows improved delineation of the external uterine contour and uterine volume.

MR imaging is superior in differentiating septate and bicornuate uterus. In a bicornuate uterus, the dividing septum is composed of myometrium, and with MR imaging it is characterized by signal intensity of myometrium. The endometrium of a bicornuate uterus has a normal width and lines two uterine cavities that communicate, as demonstrated by their confluent increased signal intensity. The contour of the fundus is concave or flattened. Finally, the bicornuate uterus typically has a significant notch larger than $1 \mathrm{~cm}$ in the fundus between the two horns, and the intercornual diameter is greater than $4 \mathrm{~cm} .{ }^{13-5}$ Bicornuate uterus may be associated with urinary tract abnormalities.

Surgical reconstruction of the bicornuate uterus has been advocated in women with multiple spontaneous abortions and in whom no other causative factors are identified. Strassman described the surgical technique that was designed to unify equal-sized endometrial cavities. ${ }^{16}$ Reproductive outcome after unification generally has been good. In 289 women, preoperative pregnancy loss was more than $70 \%$. Following surgery, more than $85 \%$ of pregnancies ended in delivery of a viable infant. The actual benefit of metroplasty for a bicornuate uterus, however, has not been tested in a controlled clinical series.

Even in the era of operative hysteroscopy, transabdominal metroplasty remains the only approach in cases of bicornuate uterus. ${ }^{17}$ Cesarean delivery is indicated following metroplasty to avert uterine rupture during labor. However, in Strassmann's series of 7,161 cases delivered vaginally there was no cases of uterine rupture during pregnancy or delivery. Despite the evidence, elective cesarean section in all patients who have undergone metroplasty is recommended.

A non-obstructed vaginal septum can be managed conservatively unless dyspareunia develops. Surgical treatment includes resection. ${ }^{6}$

\section{REFERENCES}

1. Simon C, Martinez L, Pardo F, Tortajada M, Pellicer A. Mullerian defects in women with normal reproductive outcome. FertilSteril. 1991 Dec;56(6):1192-3.

2. Grimbizis GF, Camus M, Tarlatzis BC, Bontis JN, Devroey P. Clinical implications of uterine malformations and hysteroscopic treatment results. Hum Reprod Update. 2001 Mar-Apr;7(2):161-74.

3. Rock JA, Jones HW. TeLinde's Operative Gynecology. 10th ed. Lippincott Williams \& Wilkins: USA; 2008. p. 540-85.
4. Troiano RN, McCarthy SM. Mullerian duct anomalies: imaging and clinical issues. Radiology. 2004 Oct;233(1):19-34.

5. Raga F, Bauset C, Remohi J, Bonilla-Musoles F, Simon C, Pellicer A. Reproductive impact of congenital Mullerian anomalies. Hum Reprod. 1997 Oct;12(10):2277-81.

6. Holder HJ, Strauss RS, Diana K, Richard C. Anatomic Disorders. In: Schorge JO, Schaffer JI, Halvorson LM, Hoffman 
BL, Bradshaw KD, Cunningham FG, editors. Williams Gynecology. 1st ed. McGraw Hills: USA; 2008. p. 847-52.

7. Rock JA, Jones HW, Jr. The clinical management of the double uterus. FertilSteril. 1977 Aug;28(8):798-806

8. Heinonen PK, Saarikoski S, Pystynen P. Reproductive performance of women with uterine anomalies. An evaluation of 182 cases. Acta Obstet Gynecol Scand. 1982;61(2):157-62.

9. Proctor JA, Haney AF. Recurrent first trimester pregnancy loss is associated with uterine septum but not with bicornuate uterus. FertilSteril. 2003 Nov;80(5):1212-5.

10. Buttram VC, Jr., Gibbons WE. Mullerian anomalies: a proposed classification. (An analysis of 144 cases). FertilSteril. 1979 Jul;32(1):40-6.

11. Reuter KL, Daly DC, Cohen SM. Septate versus bicornuate uteri: errors in imaging diagnosis. Radiology. 1989 Sep;172(3):749-52.

12. Woelfer B, Salim R, Banerjee S, Elson J, Regan L, Jurkovic D. Reproductive outcomes in women with congenital uterine anomalies detected by three-dimensional ultrasound screening. Obstet Gynecol. 2001 Dec;98(6):1099-103.
13. Carrington BM, Hricak H, Nuruddin RN, Secaf E, Laros RK, Jr., Hill EC. Mullerian duct anomalies: MR imaging evaluation. Radiology. 1990 Sep;176(3):715-20.

14. Fedele L, Dorta M, Brioschi D, Massari C, Candiani GB Magnetic resonance evaluation of double uteri. Obstet Gynecol. 1989 Dec;74(6):844-7.

15. Pellerito JS, McCarthy SM, Doyle MB, Glickman MG, DeCherney AH. Diagnosis of uterine anomalies: relative accuracy of MR imaging, endovaginalsonography, and hysterosalpingography. Radiology. 1992 Jun;183(3):795-800.

16. Strassmann EO. Plastic unification of double uterus; a study of 123 collected and five personal cases. Am J Obstet Gynecol. 1952 Jul;64(1):25-37.

17. Rechberger T, Monist M, Bartuzi A. Clinical effectiveness of Strassman operation in the treatment of bicornuate uterus. Ginekol Pol. 2009 Feb;80(2):88-92. 